\title{
Strategically Comparing Selected Major College Basketball Powerhouses Through The Resource Based View Of The Firm
}

David P. Synowka, Robert Morris University

Alan D. Smith, (Email: smitha@rmu.edu), Robert Morris University

Dean R. Manna, (Email: manna@rmu.edu), Robert Morris University

\begin{abstract}
The key to sustaining a competitive advantage through effective management is working with people. Especially dealing with sport management and marketing, concepts such as organizational culture and reputation are identifying strategic assets that are intangible resources. These concepts form the basis on the strategic theory behind the Resource-based View (RBV) of the firm. Strategic assets are intangible since they are inherently hard to duplicate, since duplication requires the inputs of how an object reacts with all the senses. Intangible assets are, by their very nature, 'unknowable' in the purest sense and, thus, difficult to duplicate. In addition, intangible assets are rare in that the variations that will be found within will be profound from owner to owner. The organizational cultures and reputations of the Duke University and the University of Cincinnati were compared, since they have petitions for national level basketball, but radically different organizational cultures. What constitutes organizational culture in one organization will have differences not present in another's culture, thus allowing for some teams to maintain a sustainable competitive advantage.
\end{abstract}

\section{INTRODUCTION}

\section{University Sports Programs}

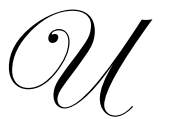

niversity sports programs have long been an important part of the culture of many universities. In fact, for a few universities, such as Duke University (DU) and the University of Cincinnati (UC), they take it even a step further. These programs have built a sports program that actually becomes a defining characteristic of the school and surrounding area. The men's basketball programs at these universities are routinely nationally ranked powerhouse that are consistently ranked at the top of the NCAA standings. For example, Durham, North Carolina, home to DU, is known as one of the greatest college towns in the country. Duke Basketball defines everything in Durham. The coffee shops, the local stores, even the neighborhood restaurants all encompass everything that is great with college sports. In this paper, the emphasis will specifically focus in on how the basketball program at DU gives them a sustainable competitive advantage via the Resource-based View (RBV), over the competition. Other universities, specifically the University of Cincinnati, will be referenced to contrast and compare our findings.

\section{Resource Based View Of The Firm}

Michalisin, Kline, and Smith $(1997,2000)$ provided a literature review of contemporary articles concerning the RBV of the firm as well as empirically testing its assumptions. The authors suggested that the RBV states that the firm's resources are the main determinant of competitive advantage and firm profitability (1997). As such, it is 
important to isolate those resources that are truly strategic and formulated an empirical model to test the validity of these hypotheses (2000). Michalisin, Kline, and Smith identified four traits shared by strategic assets, namely they are valuable, rare, non-substitutable and inimitable. Current literature on RBV does not specify which of the firm's resources would meet these classifications. They postulated that in addition to the qualifications listed above, strategic assets are also intangible, which considerably limits the possible classes of assets that fit all of the prescribed qualifications. The intangibility of resources can contribute to their strategic nature since, as being intangible, they are rare (they cannot be purchased in the open market) and they are difficult to imitate, as they are difficult to observe. Thus the qualification of intangibility to the four descriptors already supplied by other researchers. Hence, having added this qualification, they isolated three classes of assets he determines to be strategic in nature, namely employee know-how, reputation, and organizational culture, with the inclusion of each showing how all possess the characteristics of rareness, value, non-substitutability, and inimitability. All contribute to the strategic position of the firm possessing them.

The difficult assignment is to devise a method for the measurement of each of the strategic assets. As for employee know how, the measuring trademarks granted should provide an accurate indication of evidence in as much as trademarks arise out of the innovation - due to employee know-how of a firm. Traces of organizational culture would be located in annual reports, as the champion of organizational culture is typically the CEO and the CEO must sign the annual report. Finally, he believes that reputation calculations can be taken from the Forbes list of America's Most Admired Companies. With the statistical data that can be found in these various sources, there are some measurable effect of these three types of strategic assets and their effects on firm performance (as indicated by ROE). In doing so, he can provide empirical evidence for the theory of RBV.

Especially dealing with sport management and marketing, concepts such as organizational culture and reputation are identifying strategic assets that are intangible resources. Strategic assets are intangible since they are inherently hard to duplicate - duplication requires the inputs of how an object reacts with all the senses. Intangible assets are, by their very nature, 'unknowable' in the purest sense and, thus, difficult to duplicate. In addition, intangible assets are rare in that the variations that will be found within will be profound from owner to owner. In other words, what may constitute organizational culture in one organization will have differences not present in another's culture---even if they both have the same aims. This makes them rare in as much as no two will ever be exactly alike.

The description of strategic assets require that in order to achieve a strategic position in learning (which increases employee-know how) firms must focus on both training (increasing the knowledge of how things are to be done for a current responsibility) and development (expanding upon a current skill set) must be undertaken. By leveraging the framework of knowledge that is built on past information and knowledge that develops out of new information, which, essentially, is training and development. In order to be strategic, organizations must employee both types of learning. For example, the know-how of suppliers and contractors may not considered to be strategic, as the firm does not own them exclusively, are not rare. An argument could be made for strategic alliance partnerships and the know-how possessed by each party, but even under this arrangement, one or both parties can dissolve the relationship and offer the services in the open market, thus destroying the uniqueness of the asset.

Michalisin, Kline, and Smith $(1997,2000)$ and the RBV have many applications to the sport world and the mystic that develops around programs like DU and UC, but perhaps these phenomena are not new organizational forms. They are many external forces that are at play that are causing organizations to compete in new ways. One of the ways in which the organizations compete is a restructuring of the organization to be flatter and more geared towards flexibility, learning and teamwork. While these forms can, if implemented thoughtfully and correctly, contribute to a strategic advantage, caution should be taken in viewing organizational structure changes as a way of increasing strategic competence. In essence, organization structure can facilitate strategy, but it cannot create it. Time will tell with the particular structures associated with DU and UC are sustainable in the long run due to their strategic uniqueness. 


\section{CASE STUDIES}

\section{Duke University (DU)}

DU is a nationally respected educational institution, not only in the realm of sports, but with regards to the level of education the university provides. The mission of DU is to

provide real leadership in the educational world" by choosing individuals of "outstanding character, ability and vision" to serve as its officers, trustees and faculty; by carefully selecting students of "character, determination and application;" and by pursuing those areas of teaching and scholarship that would "most help to develop our resources, increase our wisdom, and promote human happiness. ("The mission of Duke University." 2004)

From a RBV perspective, if someone would mention DU to almost anyone and the consensus response you probably will receive is, basketball, due to its established reputation. This is primarily due to the fact that DU has built one of the strongest basketball programs in the nation. Under coach Mike Krzyzewski, commonly referred to as "Coach K", Duke has built a national powerhouse that is the defining identity for much of the Durham area. The economic impact of DU is staggering; DUs economic impact on the Durham area is conservatively estimated at \$2.6 billion. Visitors are an important part of the local Durham economy, representing \$227 million per year. Much of this is due to the almost cult following of the basketball fans, many of which, travel to Durham just to capture a glimpse of Cameron Indoor Stadium. The "Cameron Crazies," which are mainly Duke students, have created an atmosphere that rivals any competition in the U.S.

\section{University Of Cincinnati (UC)}

When comparing and contrasting DU to various universities throughout this paper, the focus is on UC, with specific regards to their basketball program. Each year the UC graduates 5,000 students, adding to more than 200,000 living alumni around the world. UC was chosen since it is very similar to DU in many aspects. The mission of UC is as follows: "the University system is designed to serve a diverse student body with a broad range of interests and goals. It is a place of opportunity" ("The mission of Cincinnati University." 2004).

The UC is the largest employer in the Cincinnati region, with an economic impact of more than $\$ 3$ billion per year. UC has a tremendous medical school and various academic programs that have produced many pioneering ideas. They were the first university in the country to establish a cooperative education program. With regards to their medical advancements, UC was the first to develop an electronic organ, the first antihistamine, and UC also developed the oral polio vaccine. UC has an enrollment of over 33,000 undergrad and graduate students, with about $87 \%$ being residents of the state of Ohio. UC has five medical programs that are recognized in the top 50 in the country. UC is a nationally recognized educational institution, renowned for many medical and educational firsts. For all of UCs successes in the classroom and in the medical field, this may not be what the general public correlates with the UC. Why is this? Probably the answer is simple due to the predominance of its athletic programs. The UC men's basketball program has long been a very prolific and successful team on the court. Unfortunately, off court the UC men's basketball team has built another reputation. Graduation rates at the UC have long been very low; a few years they have even graduated no athletes from the basketball team.

\section{Role Of The Resource-Based View (RBV) Of The Firm}

Since the RBV suggests that strategic assets determine sustainable competitive advantage and, in turn, drive a firm's performance. Resources, are all assets, capabilities, organizational processes, firm attributes, information, knowledge, that controlled by a firm that enable a firm to conceive of and implement strategies that improve its efficiency and effectiveness (Michalisin, Kline, and Smith, 1997, 2000). These resources can be of the physical capital, human capital, or organizational capital variety. They also can be tangible or intangible according to Porter (1991, 1996). By definition, tangible resources are physical in nature, and, thus, capable of being imitated. Since resources must be imperfectly imitable to be considered strategic assets, we must look to intangible resources to 
obtain a sustainable competitive advantage. Simply put, this means strategic assets are intangible resources, according to the RBV.

According to the RBV, the types of strategic assets that both meet their criteria and lead to sustainable competitive advantage are reputation (both product and company), employee know-how, and organizational culture. For the purposes of this paper, the strategic assets of reputation and organizational culture are reviewed as drivers of competitive advantage and positive organizational performance. These, it is the opinion of the authors, that these intangible strategic assets that set DU men's basketball program apart from other universities, even when compared to programs like UC.

Generally speaking, reputation is not formed overnight. It takes many years and much effort to establish the way an organization is viewed from those outside it. First, an organization has to decide how it wants to be viewed, and then it has to go about the task of accomplishing that goal (Peters, 2003). Since Krzyzewski was named head coach of DU in 1980, only two players that played four years for him did not graduate ("Success," 2004). This may be due to the coach's requirement that DU has a respected program and is concerned with the success of the studentathletes, both on and off the basketball court. The program has a stellar reputation, since it consistently ranks as one of the top teams in the country, while maintaining graduation rates that are significantly higher than many other similar programs.

UC, on the other hand, does not have the reputation associated with DU; for example, during the reign of Coach Bob Huggins, UC went a seven-year stretch without graduating a single basketball player ("Taste - review \& outlook ..." 1999), without a national championship during this time as well. The basketball program at UC clearly does not compare favorably to that of DU, either on the court or in the classroom, as far as reputation is concerned. At DU, organizational culture also plays a role in distancing the university from competitors like UC. DU and its coach stress the importance of being a "student-athlete" and not just an athlete. In fact, DU graduates a higher percentage of its basketball players than the national average of all students in Division I schools, 67\% at DU as compared 57\% for all students (Clarke, 2004).

In addition, DU tries to maintain a family closeness that adds to the positive culture, illustrating a desire to promote the personal success of its players. To that end, the DU formed the Student Athlete Career Counseling Committee (SACCC) to help its sport stars' negotiate professional contracts with sports agents (Morgan, 1995). This is an example of how the organizational culture of DU contributes to its competitive advantage.

On the other hand, UC may not have the same regard for the future well being of its players. A recent graduation rate for UC basketball players stood at 8\% ("NCAA basketball tournament ..." 2002). As seem during broadcasting of games, Coach Huggins routinely berates his players and has seen his team put on probation because of shady dealings concerning its players. Huggins has a history of recruiting athletes with less-than-stellar academic histories, and he has recruited players with legal troubles (Gildea, 1999). The culture appears to be more focused on winning rather than the graduation rates of its student-athletes.

Reputation and organizational culture, as demonstrated above, contribute to the sustainable competitive advantage and performance success DU maintains over other universities such as the UC. By maintaining high academic requirements and expectations for its student-athletes, DU positions itself for continued success on the basketball court. For example, if a high school basketball player meets the academic and athletic requirements of DU, he/she may be more successful for promoting education as opposed to an institution such as UC if the present situation remains unchanged. Simply put, according to Gildea (1999), "Duke is a better school for athletes," as suggested by at least one UC professor (Gildea, p. 3).

Although much can be discussed about the merits of sustainable competitive advantage and organizational performance, but how can they be appropriately measured? Apparently, for DU, a classically approach is to combine performance on the basketball court and in the classroom, namely through graduation rates (although some say that graduation rates alone may avoid the integrity of the majors or lower standards for athletes in order to achieve artificially graduation rates). Looking at performance on the hard-court, using DU and UC as the competitive 
barometers, Coach Ks tenure at DU, the basketball team has made the Final Four ten times, winning three NCAA National Championships. Cincinnati has made the Final Four one time during that same stretch with zero NCAA National Championships to show for their efforts. In addition, Coach $\mathrm{K}$ has averaged nearly 1.5 NBA draftees per year during his stay in Durham (Brill, 2004; "MK" 2004). Coach Huggins, on the other hand, has averaged less than one NBA draftee per year during his tenure in Cincinnati.

The other significant arena in which DU outperforms the UC is in the academic classroom. As previously mentioned, UC graduates basketball players in the single digit percentages, while Duke graduates a minimum of twothirds of its basketball players during the Coach K regime. Simply put, Duke's players are in an organizational culture that proliferates winning, while maintaining relatively high academic standards for its student athletes. The reputation of an academic institution reflects the positive aspects of that combination. On the other hand, Cincinnati has focused on winning with a seemingly reduced concern for academics, truly reducing its players to athletes as opposed to student athletes, as reflected with a zero graduation rate for its African American basketball players. Despite UCs focus, Duke's program continues to outperform that of UCs program on the court as well. In utilizing the RBV of the firm to analyze and compare DU and UC, DU has decidedly achieved sustainable competitive advantage that is extremely difficult to imitate and copy with any success.

\section{DU AND ITS IMPACT ON THE LOCAL ECONOMY}

\section{Revenue-Generation Functions}

According to the Office of Public Affairs at DU, it was estimated that the university's total economic annual impact on the city and county of Durham, NC in 2003 was $\$ 2.6$ billion. This figure is broken out into direct and indirect benefits for the city ("An analysis of Duke University's estimated..." 2004; "Big impact" 2004). The direct benefits include employment, goods and services, taxes and fees, donations, and uncompensated medical care provided by the DU Health System for Durham County residents. The indirect benefits result from the spending in the city and county of Durham by students and campus visitors. DUs largest contribution to the city and county of Durham is in wages and benefits. DU is the largest employer in Durham, NC. Over eighteen thousand residents are employed at the university adding up to $\$ 732$ million being paid in wages and benefits. These residents account for $52 \%$ of the university's employees. DU was the fourth largest non-governmental employer in the state of North Carolina in 2000 . The average salary for a DU employee was approximately $\$ 63,000$, with hourly employees earning an estimated $\$ 37,000$ a year. DU attracts a highly skilled and educated work force to the campus, partially due to the number of grants and expenditures for medical research. These grants and expenditures, $\$ 365$ million annually, create jobs for graduates and students and as a result, have led to the creation of over 15,000 jobs in the past four years. According to Thomas White, President of the Greater Durham Chamber of Commerce, DU plays a pivotal role in helping the region conduct an aggressive and effective economic development program that produces good jobs at good wages, with North Carolina ranked third in the nation in biotechnology enterprises and Durham being home to approximately one-half of those operations that do business in the state. (2003 state of Durham's economy report." 2004; “University's impact on Durham hits \$2.6B." 2004). In perspective to Porter's (1991, 1996) Five-force Model, DUs presence as being the largest employer in the Durham area has allowed them to create a high barrier to entry for other competing concerns the Durham area.

The second largest activity contributed by Duke to the Durham community is purchasing of goods and services from local businesses and individuals. The university's spending in 2003 was estimated at a total of $\$ 811$ million in goods and services with $\$ 188$ million being spent on construction for new contracts and professional architecture and design services. Much of Duke's other spending of its local goods and services are dominated by transactions with small firms and individuals. In relation to Porter's Five Force Model, the purchasing of goods and services by DU has created a powerful bargaining tool for Duke to use with the Durham community. As a result, DU finds itself in a great position as having a sustainable competitive advantage over any other university not only in Durham, but within the state of North Carolina.

Annual recurring donations from DU account for $\$ 51$ million of the $\$ 1.3$ billion impact on the Durham community. Of that total, Duke provides $\$ 48$ million of uncompensated medical care to the residents of Durham 
through its University Health System. In relation to Porter's Five Force Model, Duke's donations, being annual, create a sustainable competitive advantage amongst any other university institution. When looking at the bargaining power of the customer, in this case, the Durham community, the residents of Durham believe that no other college or university would donate as much as Duke has for them in the past and the upcoming future. The residents have seen and experienced the value the university has brought to the community, which creates a clear, competitive edge for Duke over any other schools. The Durham community continues to receive a large amount of support and benefits from DUs programs and activities. Student and visitor spending accounts for approximately $\$ 300$ million a year, constituting the most significant impact on spending being brought into Durham. Under the student-spending sector, it is estimated that between undergraduate and graduate/professional students, they will spend an estimated $\$ 89.5$ million annually. DU has become the most popular destination of visitors to the Durham area. Strategically leveraged by prospective students from high schools across the country and Duke athletic events (men's basketball being the lead reason), it is estimated that the Duke visitor spending amounted to \$227 million in 2003, with the outcome for 2004 to be similar if not higher than 2003. As mentioned previously, DUs student and visitor spending in the Durham community can act as a bargaining tool for the university against any other schools that may want to enter the Durham area. Not only has DU contributed to Durham economically, but also the university offers other intangible assets to the residents of Durham such as intellectual and cultural stimulation, entertainment, and recreational opportunities. Having these intangible assets along with its reputation as being an academically and athletically challenging school, DU will continue to sustain its competitive advantage over any other schools already in or wanting in Durham. DU will continue to maintain its established partnership with the city and county of Durham in providing activities and benefits that will improve the lives of Durham residents.

\section{Recruiting and Coaching Activities}

Recruiting has traditionally been the bloodline of collegiate athletics. DU and its basketball program are members of the elite Atlantic Coast Conference (ACC), a conference where recruiting often takes care of itself. Programs like DU and its ACC members are in a league of their own when it comes to recruiting new talent. Toplevel high school talent wanting to take their abilities to the next highest level often seeks out teams in the ACC. Therefore, the elite schools can be selective in who they bring into their respective programs. For example, in 2004, DU athlete Luol Deng, who was only a freshman, decided to enter the NBA professional draft. They also lost recruit Shaun Livingston, who signed with DU out of high school, but has since decided to skip college altogether and enter the pro draft. Still, DU will start four McDonald's All-Americans, including standout J. J. Reddick, at least partially due to the reputation and successful recruiting and being a member of NCAA Division I elite conference. The class of 2004 includes two true freshmen, both of which were high school All-Americans.

In an attempt to differentiate himself and his program, Coach $\mathrm{K}$ has focused more on just recruiting pure talent. He seeks players that will not only thrive on the basketball court, but those who will thrive in the classroom and thrive in the community. When is the last time there was mention of a Duke player being arrested for anything? The answer is never. Coach Ks philosophy is more than just player talent; he did not build Duke's tradition and national power simply on recruiting the best talent. His philosophy extends into commitment, toughness, honesty, integrity, collective responsibility, pride, love and friendship (Clarke, 2004). In 23 years, Coach $\mathrm{K}$ has built a dynasty and has been recognized nationally as coach of the year twelve times. When he recruits a player he makes no promises of winning, no guarantees of playing time. He tells his recruits that it will be up to the recruit to come in, work hard, and earn everything they receive.

DU has the numbers to back up their claim as an elite program. Since 1986, 51 of 55 players who have completed four years of eligibility at Duke have participated in a final four and at least one national championship. ("More quotes from Coach K." 2004). Coach K has led Duke to 10 Final Four appearances, winning the national title three times. They played in five consecutive Final Fours and for four consecutive years finished the season ranked number one. Six years in a row, Duke was champion of the ACC and six times had the national player of the year. National players of the year are the product of an excellent team (Brill, 2004; "Success." 2004). It is these statistics that will continue to attract the best talent to DU. 
A book often referenced is a book written by Coach $\mathrm{K}$; at the end of each chapter he lists quotes and coaching tips. Some of his wisdom on a winning team that embraces the spirit behind intangible assets defined in the RBV includes the following (Krzyzewski and Phillips, 2000):

- Leaders instill respect for authority by having a caring attitude, by being direct, by communicating regularly, and by being honest.

- $\quad$ People have to know that your word is good.

- $\quad$ Failure is part of success.

- $\quad$ Teach good sportsmanship, patience, and the idea that people should be enthusiastic and energized every time out.

- Tradition helps motivate people. It makes them want to come back. They desire to go on another journey.

- $\quad$ Once tradition is in place, confidence, excellence, unity, and pride will grow.

When you play for DU under his leadership, you are taught life lessons focusing on life and leadership. He shows his players the importance of a strong work ethic and being part of something bigger than themselves. In general, DU basketball wins with humility and loses with dignity. Throughout his 23 years, Coach $\mathrm{K}$ has created a "Duke experience" for his players that extend beyond just scoring points and grabbing rebounds.

Hence DU has built on its reputation by becoming an icon in sports. Cameron Indoor stadium adds to that culture. In fact, it is in the same breath as Wrigley Field, Yankee Stadium and Fenway Park with respect to our generation's greatest venues. From the outside Cameron Indoor Stadium is a refurbished and not air-conditioned building that is due for replacement into a modern 40,000 capacity stadium. However, Cameron Indoor Stadium has become a tradition that can never be rebuilt once it's gone. In 1999, Sports Illustrated ranked Cameron as the number four active venues for sports in the twentieth century (Brill, 2004; "Success." 2004).

\section{Strategic Recommendations}

In essence, intangible strategic assets should be rare, intangible and not imitable so in order to create a competitive advantage, which is abundantly clear with DU and obviously lacking with UC in terms of men's basketball. The three types of assets that the authors list as falling into this category included employee know-how, organizational culture, and reputation. The authors' assumptions were that the verifiable presence of these three classes of intangible assets would increase firm performance over short, intermediate and long-term time horizons. There are a number of strategic recommendations that can be made in the spirit of the RBV: Leverage and build relationships with sponsors, promote success of alumni, both in sports and business, Expand academic programs, modeling after the medical program, Leverage basketball success to other university sports programs, and Develop "branch campuses" to grow the reputation of DU.

- $\quad$ Leverage and Build Relationships with Sponsors: Advertising and promoting the university is one of the most expensive, but most effective ways to build and expand a sports program. Being that DU already has a longstanding relationship with many companies, such as Nike, they can build and expand on these relationships, Leverage basketball success to other university sports programs, and Develop "branch campuses" to grow DU.

- $\quad$ Promote success of alumni, both in sports and business: It is no secret to anyone who follows DUs sports to see that the Alumni achieve a high success rate after graduation. However, the success of graduates should be advertised to the outside world. This will show that DU not only cares about on court success, but also prepares the athlete for a future after basketball.

- $\quad$ Expand academic programs, modeling after the medical program: With Duke's medical program being such a strong asset to the university, the university should look into investing in other academic programs (business management, law, or fine arts), developing a similar type of reputation of their medical program, allowing them to become more diversified in its curriculum. In doing so, this will lead to areas of expansion and growth for the university.

- $\quad$ Leverage basketball success to other university sports programs: In relation to Duke's athletic programs, it has been labeled as the basketball capital of the US because of the success of their men and women's teams. 
It is recommended that they use their successes in these sports as leveraging tools in recruiting athletes for their other sports, such as football, baseball, and soccer.

- Develop "branch campuses" to grow the reputation of DU: Duke should look into branching out their curriculum to areas outside of Durham within the state of North Carolina as being branch campuses of DU.

\section{REFERENCES}

1. An analysis of Duke University's estimated total annual economic impact on the city and county of Durham. (2004, November). [Online]. Available: http://www.dukenews.duke.edu/economicbooklet.pdf.

2. $\quad$ Big impact (2004). Duke Dialogue Newsletter. [Online]. Available: www.dukenews.duke.edu/news/dialogue_newsrelease5bee.html.

3. $\quad$ Brill, B. (2004). 100 Years of Duke Basketball. Sports Publishing LLC.

4. $\quad$ Clarke, L. (2004, March 23) Graduation rates lagging for advancing teams. The Washington Post, p. D-06.

5. Drape, J. (1999, March 19). At Duke, the course is Coaching 101 New York Times (Late Edition (East Coast), p. 5 .

6. Gildea, W. (1999, February 19). Amid controversy, Huggins stands tough; Cincinnati basketball coach weathers criticism of his in-your-face style and his program. The Washington Post, p. D-1.

7. Kindred, D. (1999, February 22). Coach K's team has no '1.' Sporting News, 223(8): p. 62.

8. Krzyzewski, M. and Phillips, D. (2000). Leading with the Heart. New York: Warner Books, Inc.

9. Michalisin, M. D., Smith, R. F., and Kline, D. M. (1997). In search of strategic assets. The International Journal of Organizational Analysis, 5(4): 360-387.

10. Michalisin, M. D., Kline, D. M., and Smith, R. F. (2000). Intangible strategic assets and firm performance: A multi-industry study of the resource-based view. Journal of Business Strategy, 17(2): 91-117.

11. "MK." (2004). Collegesports.com. [Online]. Available: http://goduke.collegesports.com/sports/mbaskbl/mtt/krzyzewski_mike00.html.

12. More quotes from Coach K. (2004). Coach K's Website. [Online]. Available: http://www.coachk.com/quotes.htm.

13. Morgan, J. (1995, April 6). The transition team: Duke form's committee to guide its sports stars into the pros. Black Issues in Higher Education, 12(3): 27.

14. NCAA basketball tournament; Stanford would shine in this final four; academics: cardinal boasts best graduation rate for teams in the men's tournament field. (2002, March 23). Los Angeles Times, p. D-9.

15. Pearce, J. A (2004). Strategic Management; Formulation, Implementation, and Control. New York: McGraw-Hill College, 2004.

16. Peters, J. (2003). Branded! Measuring Business Excellence. 7(4): 57-58.

17. Porter, M. E. (1991). Towards a dynamic theory of strategy. Strategic Management Journal, 12: 95-117.

18. Porter, M. E. (1996, November/December). What is strategy? Harvard Business Review, 74(6): 61-78.

19. Taste - review \& outlook: They got game. (1999, May 19). Wall Street Journal (Eastern Edition), p. W-17. .

20. The mission of Cincinnati University. (2004). University of Cincinnati Website. [Online]. Available: www.uc.edu/ucinfo/mission.htm.

21. The mission of Duke University. (2004). Duke University Website. [Online] Available: www.planning.duke.edu/mission.html.

22. Success. (2004). [Online]. Available: http://goduke.collegesports.com/sports/m-baskbl/spec-rel/coach-k-offcourt.html.

23. University's impact on Durham hits \$2.6B. (2004). The Chronicle Online. [Online]. Available: www.chronicle.duke.edu/vnews/display.v/ART/2004/02/13/402cc78bd4f80.

24. 2003 state of Durham's economy report. (2004). Durham, NC. Website. [Online]. Available: www.durhamnc.com/secondary/SODE2003/index.php. 